\title{
INTERACTION BETWEEN INTERPLATE TOPOGRAPHY AND TSUNAMIGENIC STRUCTURES AT THE SUBDUCCION ZONE OFFSHORE W MEXICO
}

R. Bartolome ${ }^{1}$, M. Prada ${ }^{1}$, C. Gras ${ }^{1}$, S. Begovic ${ }^{1}$, F. Awkar ${ }^{1}$, W.L. Bandy ${ }^{2}$ and J.J. Dañobeitia ${ }^{3}$
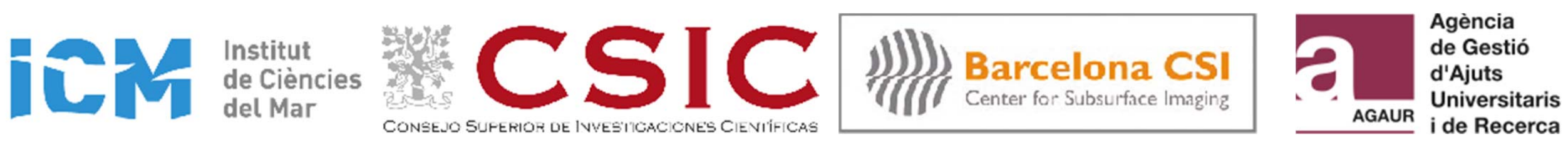

(1) Instituto de Ciencias del Mar-CSIC, Barcelona, Spain

(2) Instituto de Geofísica, UNAM, México, D.F.

(3) Unidad de Tecnología Marina - CSIC, Barcelona, Spain

rafael@icm.csic.es 
a)

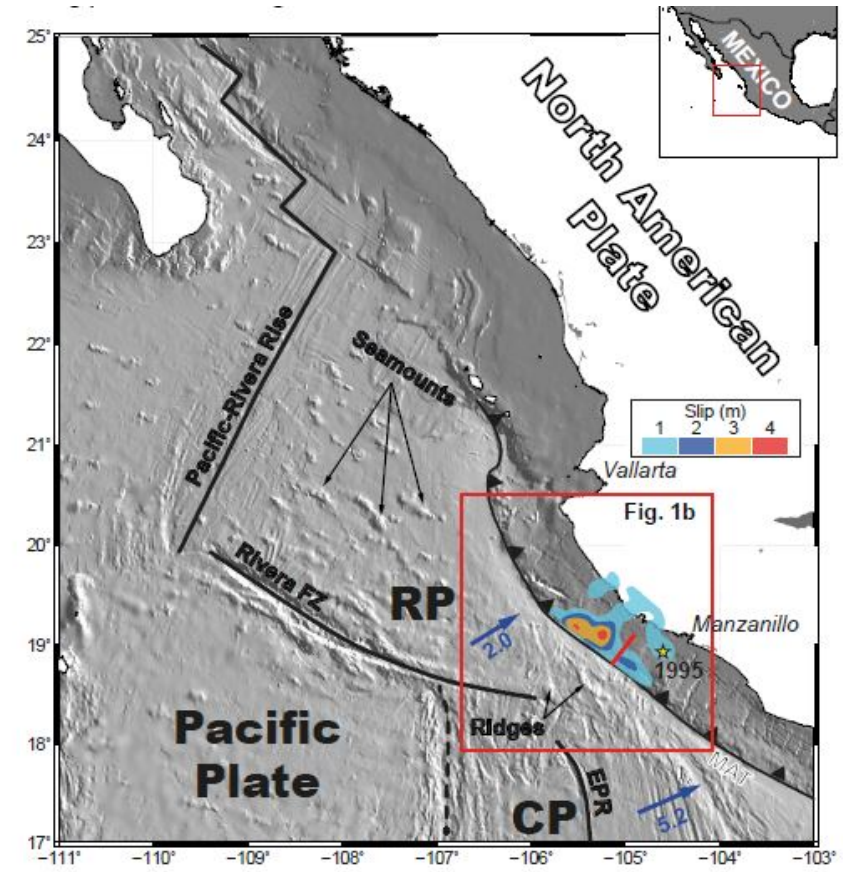

b)

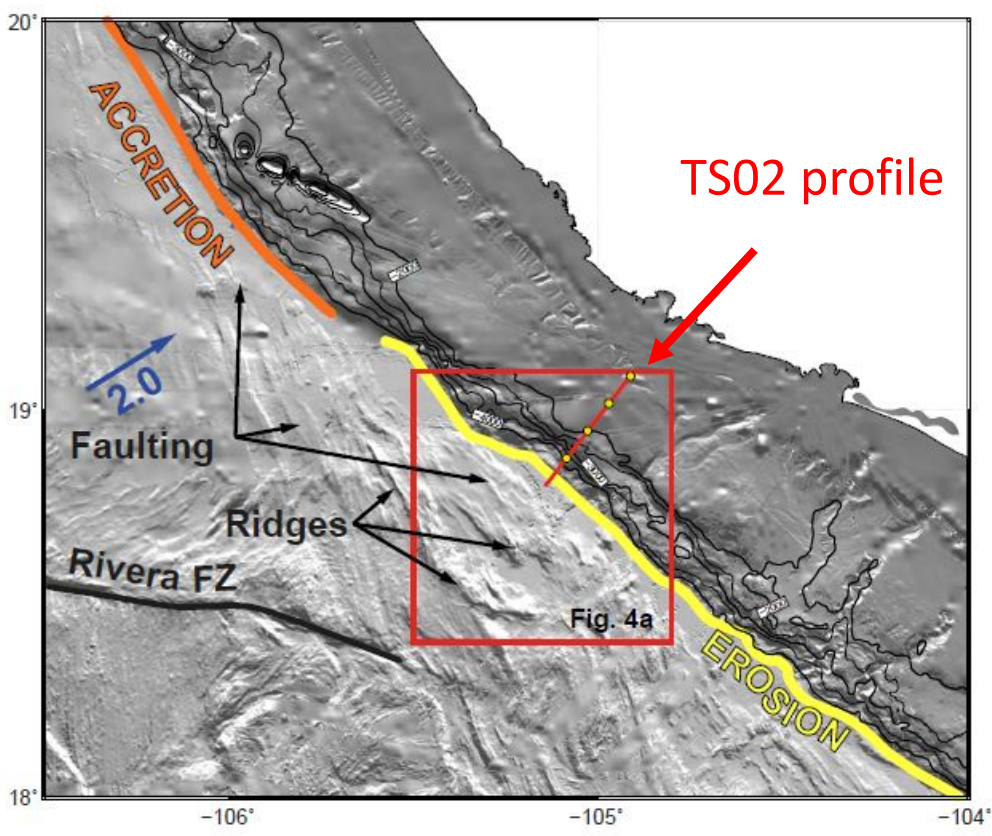

\section{GOAL OF THE WORK:}

Study of the megathrust topography role in the generation of tsunamis, by conditioning the tsunamigenic structures of the overriding plate We use line TSO2 that have been acquired with multichannel seismic and ocean bottom seismometers in 2014, perpendicular to the margin

\section{TECTONIC SETTING :}

1. The Rivera subduction zone (W Mexico) hosts large megathrust tsunamigenic earthquakes (Mw >7.5) and rarely known tsunamigenic structures

2. Tectonic structures with several sizes and shapes as ridges and seamounts are located in the plate seafloor travelling towards the trench

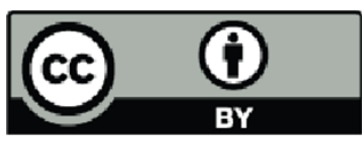


a)

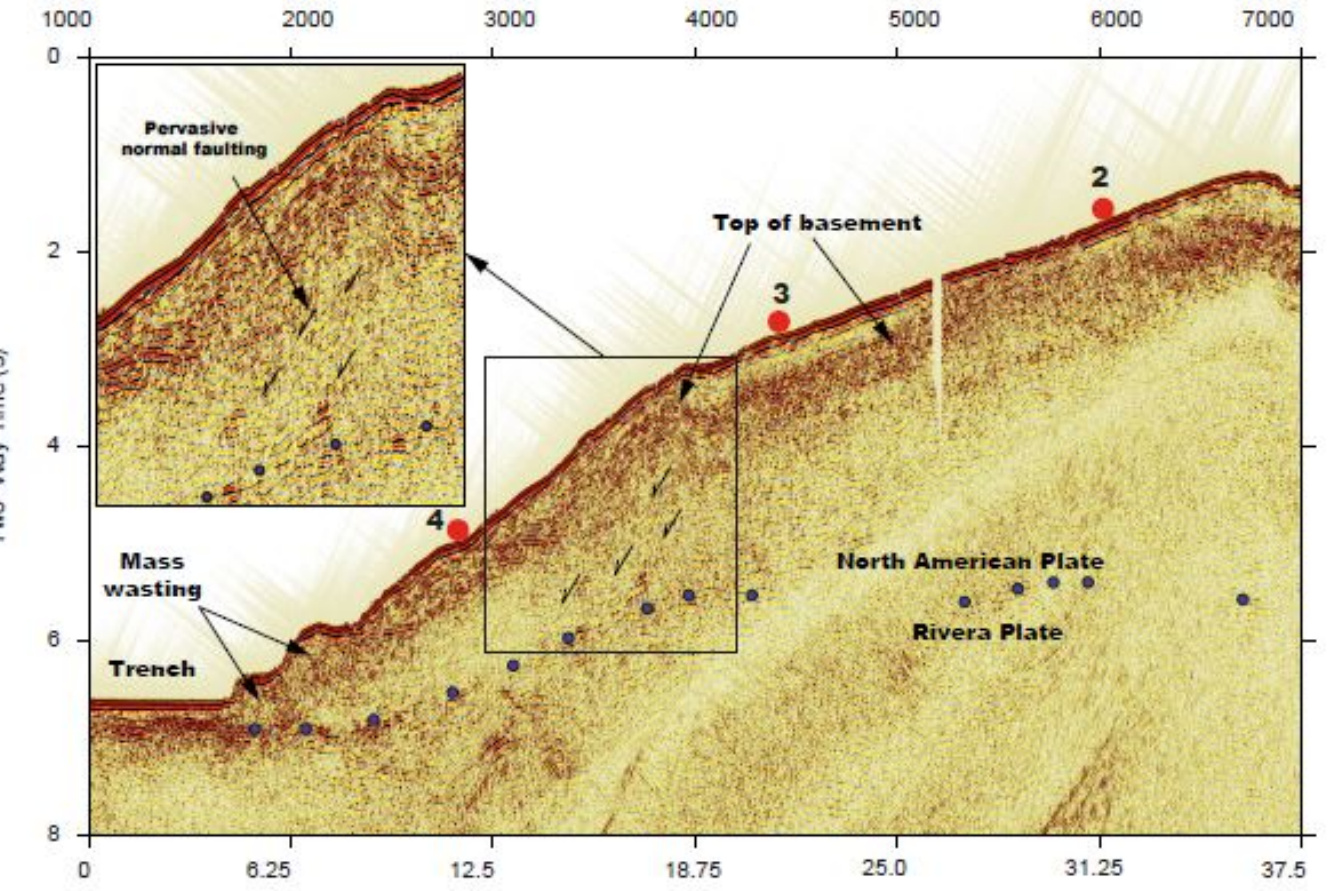

TECTONIC STRUCTURE:

a) No accretionary prism: subduction erosion type of margin

b) Seismic profiles imaging pervasive normal faulting in the overriding North American Plate

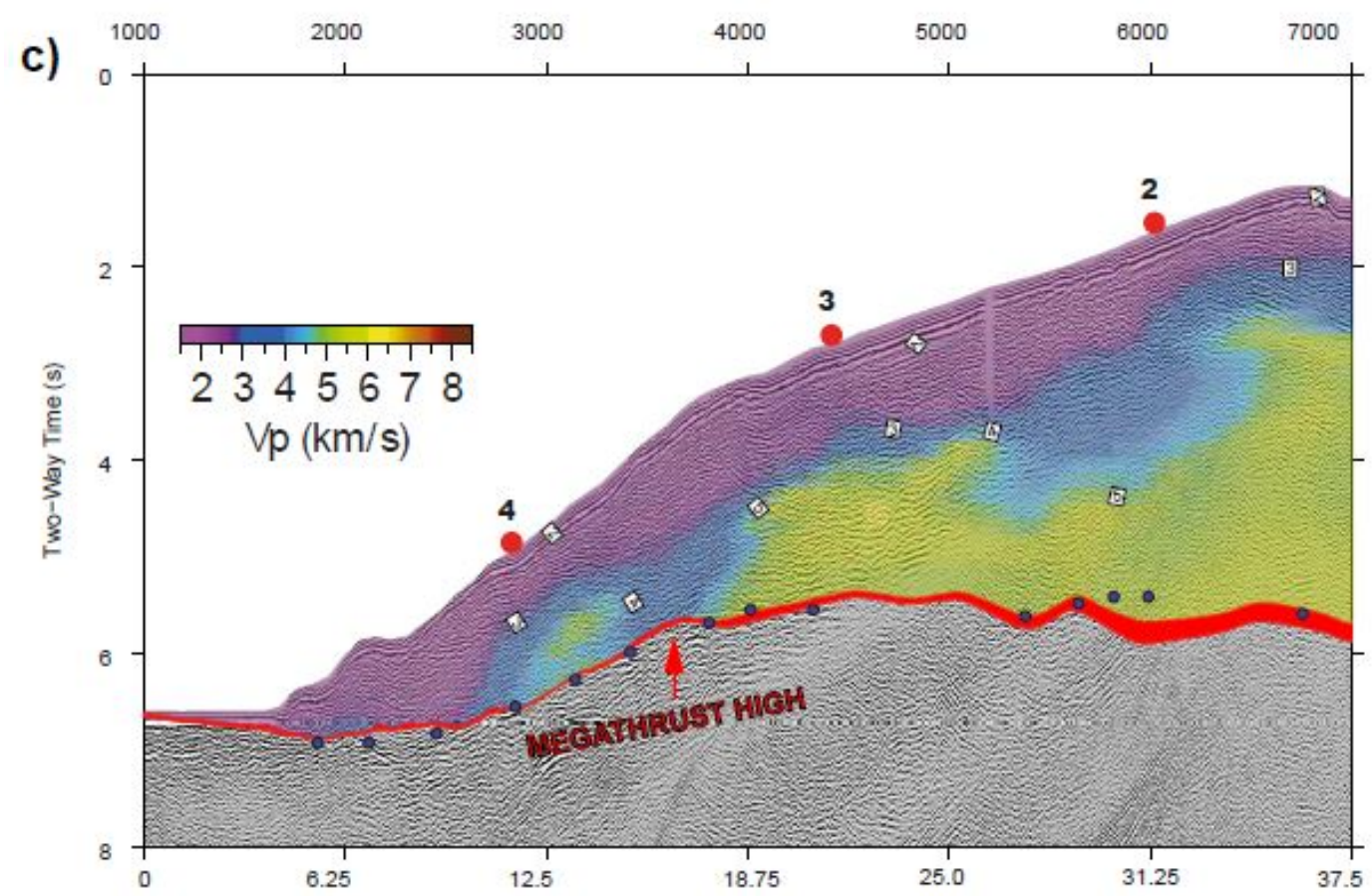

TOMOGRAPHIC P-WAVE MODEL ONTOP MCS SECTION:

a) Red band is the inverted megathrust interface using jointly reflected travel-times from MCS field data and OBS data

b) Megathrust high is present at CMP 3500

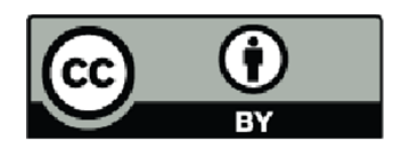




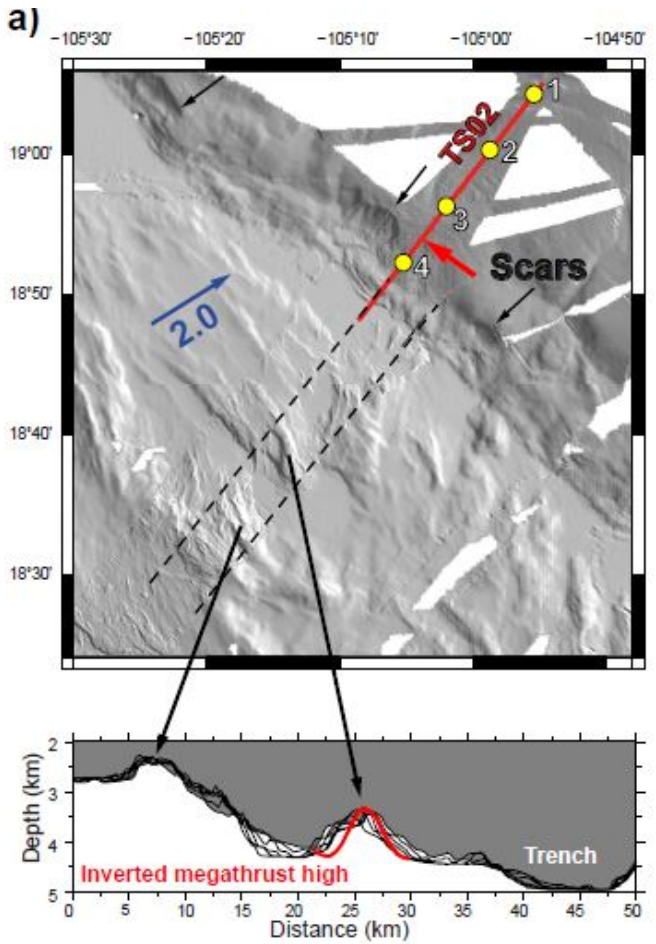

RESULT \#1:

The inverted megathrust high in the shallow domain is comparable in size ad shape with some of the incoming ridges observed in the bathymetry of the Rivera Plate b)

c)
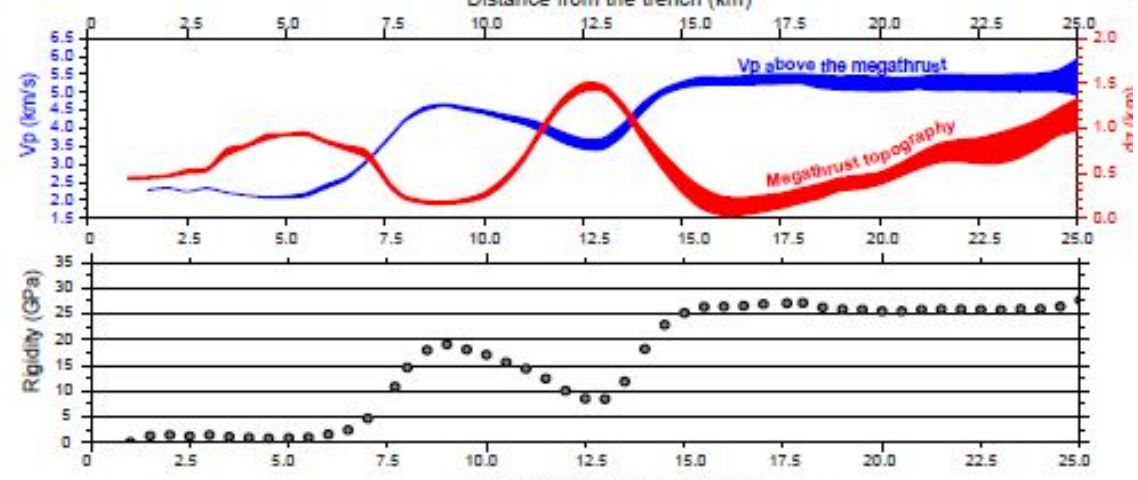

d)

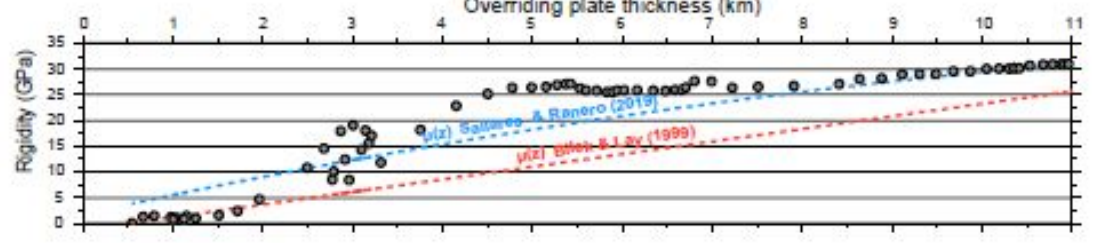

\section{RESULT \#2:}

P-wave low velocity anomalies of the tomographic model corresponds with highly faulted áreas in the seismic image

\section{RESULT \#3:}

The shallow area of the megathrust is the most affected zone by local topographic variations of the incoming plate

\section{(c) (1)}




\section{CONCLUSIONS:}

Our work demonstrates the strong control that megathrust topography has on:

1. the convergent margin style (subduction erosion)

2. the tectonism (normal faulting) in the overriding plate

3. the elastic properties (velocity and rigidity)

\section{THEREFORE:}

The megathrust topography favors tsunamigenesis (low rigidity and slope failure) in the Rivera Plate, offshore W Mexico

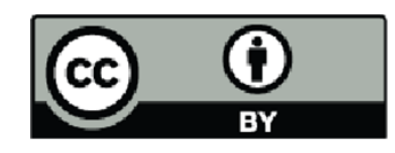

